\title{
Características clínicas, moleculares e laboratoriais de crianças com doença falciforme do Rio de Janeiro
}

\author{
Clinical, molecular and laboratory characteristics of children with sickle cell disease in Rio de Janeiro
}

Isaac Lima da Silva Filho

Orientador: Maria José de Andrada-Serpa

\section{Resumo}

A inclusão das hemoglobinopatias no Programa Nacional de Triagem Neonatal (PNTN) nos reserva a oportunidade única de entender melhor a história natural da doença falciforme (DF) na nossa população. Objetivo: O estudo investigou características clínicas, moleculares e laboratoriais de crianças com DF do PNTN do Rio de Janeiro a fim de identificar fatores de risco que levariam a um melhor ou pior prognóstico. Métodos: A determinação do genótipo da hemoglobina das crianças foi realizada por cromatografia líquida de alta pressão. A determinação dos haplótipos do grupamento dos genes da globina $B S$ e $B C$, das mutações na metilenotetrahidrofolato redutase (MTHFR), Fator V (FV) e protrombina (PT) foram realizadas por reação em cadeia de polimerase (PCR) e análise dos sítios polimórficos utilizando endonucleases de restrição (RFLP). As mutações alfa3.7 e alfa4.2 no gene alfa foram investigadas por PCR. Resultados: A amostra foi composta por 124 crianças com DF, idade de 1-180 (57,3 $\pm 56,1)$ meses, 107 com anemia falciforme (AF) e 17 com hemoglobinopatia SC. Os haplótipos foram identificados em 123 crianças, 53 (43,1\%) Bantu/Bantu; 36 (29,3\%) Bantu/Benin; 18 (14,6\%) Bantu/Atípico; 3 (2,4\%) Benin/ Benin; 2 (1,6\%) CI/Atípico; 7 (5,8\%) Bantu/CI; 2 (1,6\%) Benin/CI e $2(1,6 \%)$ Benin/Atípico. A talassemia alfa3.7 foi estudada em 118 crianças, sendo $19(16,1 \%)$ heterozigotas e $3(2,5 \%)$ homozigotas. A mutação C677T da MTHFR foi estudada em 111 crianças onde $23(20,7 \%)$ foram heterozigotas e $4(3,6 \%)$ homozigotas. Não foi observada deleção alfa4.2 no gene alfa, assim como não encontramos as mutações G1691A no gene do FV e G20210A na PT. Foram registrados 726 eventos clínicos em $94 \%$ das crianças, que foram os seguintes: hepatomegalia (32), esplenomegalia (103), icterícia (6), dor (110), sequestro esplênico (89), crise hemolítica (127), dactilite (54), infecção (192), síndrome torácica aguda (11), priapismo (1) e acidente vascular encefálico (1). Crianças Bantu/Atípico apresen- taram 9,8 vezes mais chances $\mathrm{OR}=9,86$ (CI 95\% 2,8-35,1) de acidente vascular encefálico do que aquelas de outros haplótipos avaliados. Conclusões: A AF é uma doença grave já na primeira infância e os haplótipos da globina beta e a talassemia alfa parecem influenciar a expressão clínica da doença.

Descritores: Anemia falciforme; Polimorfismo genético; Acidente cerebral vascular; Sinais e sintomas

\section{Abstract}

The inclusion of hemoglobin $\mathrm{S}$ tests in the neonatal screening program provides an opportunity to better understand the natural history of sickle cell disease in the Brazilian population. Objective: To investigate phenotypic, molecular and laboratory features of sickle cell disease children in order to identify risk factors related to prognosis. Methods: Sickle cell disease screening was carried out by high performance liquid chromatography. The beta-globin gene cluster, methylenetetrahydrofolate reductase (MTHFR-C677T), Factor V Leiden (FV-G1691A) and prothrombin (PT-G20210A) gene mutations were investigated by polymerase chain reaction restriction fragment length polymorphism. Alpha ( $3.7 \mathrm{~kb}$ and $4.2 \mathrm{~kb})$ thalassemia deletions were determined by polymerase chain reaction. Results: One hundred and twenty-four children with a mean age of 57.3 months (range 1-180) were investigated. One hundred and seven had sickle cell anemia and 17 had hemoglobin SC. Beta-globin gene haplotypes were identified for 123 children: 53 (43.1\%) Bantu/ Bantu, 36 (29.3\%) Bantu/Benin, 18 (14.6\%) Bantu/atypical, 3 (2.4\%) Benin/Benin, 2 (1.6\%) CI/ atypical, 7 (5.8\%) Bantu/CI; 2 (1.6\%) Benin/CI and $2(1.6 \%)$ Benin/atypical. The alpha $3.7 \mathrm{~kb}$ thalassemia mutation was found in 118 children, $19(16.1 \%)$ were heterozygous and $3(2.5 \%)$ homozygous. No alpha 4.2 mutation was found. Among

Fundação Oswaldo Cruz - FIOCRUZ - Rio de Janeiro (RJ), Brasil.

Recebido: $21 / 9 / 2010$

Aceito: 24/9/2010

Correspondência: Isaac Lima da Silva Filho

Fundação Oswaldo Cruz - FIOCRUZ

Av. Brasil, 4365 - Manguinhos

21040-360 - Rio de Janeiro (RJ), Brasil

E-mail: filho40@gmail.com 
111 children analyzed, 27 presented the MTHFR gene mutation with $23(20.7 \%)$ being heterozygous and 4 (3.6\%) homozygous. No Factor V Leiden or prothrombin mutations were identified. Standard forms were used to record clinical events. Seven hundred and twenty-six events occurred in $94 \%$ of the children including: infection (192), hemolytic crisis (127), painful crisis (110), splenomegaly (103), acute splenic sequestration (89), hand-foot syndrome (54), hepatomegaly (32), acute chest syndrome (11), jaundice (6), priapism (1) and stroke (1). Children with the Bantu/ atypical haplotype had a 9.8 times higher risk $(\mathrm{OR}=9.86$ : $95 \% \mathrm{CI}$ 2.8-35.1) of strokes than those with the Bantu/Benin and Bantu/ Bantu haplotypes. Conclusion: Sickle cell anemia is a severe disease starting early in life. Beta globin haplotypes and the presence alpha thalassemia seem to influence the phenotype of this disease.

Keywords: Anemia, sickle cell; Polymorphism; Genetic; Stroke; Signs and symptoms

Avaliação: A RBHH publica os resumos e abstracts de teses da área apresentados em entidades que tenham programas de pós-graduação reconhecidos pelo MEC/Capes e considera a obtenção do título suficiente para sua publicação na forma como se propõe a seção. 